\title{
Successful Kidney Transplant for Nephropathic Cystinosis in a Patient with Von Willebrand Disease Type III: The First Case Report
}

\author{
Mohammad Khaled Alsultan $^{\mathrm{a}}$ Zeina Nizar Bdeir ${ }^{\mathrm{a}}$ Qussai Hassan ${ }^{\mathrm{b}}$ \\ Tahani Alic \\ aDepartment of Nephrology, Al Assad and Al Mouwasat University Hospital, Damascus, \\ Syria; ' Prof and Chief of Nephrology Department, Al Assad University Hospital, Damascus, \\ Syria; 'Chef of Laboratory Section at Gynecology and Obstetrics University Hospital, \\ Damascus, Syria
}

Keywords

Nephropathic cystinosis · Von willebrand type III · Kidney transplantation

\section{Abstract}

Nephropathic cystinosis (NC) is a rare autosomal recessive disease, which causes cysteinecrystals accumulation with progression to end-stage renal disease (ESRD). Von willebrand disease (VWD) type III is a rare subtype of von willebrand factor (VWF) abnormality, which is characterized by severe reduction of VWF and factor VIII activity. A 16-year-old patient with NC and VWD type III presented with uremic symptoms due to ESRD. Dialysis access was inserted and followed by hemodialysis (HD) for 4 months with a proper infusion of blood products. While renal transplant remains the treatment of choice of NC and superior to chronic HD, bleeding complications were a major concern in this case with coexisting VWD type III. However, with the meticulous implementation of the Hematology team's daily recommendations, renal transplantation was successfully performed. This is the first case that mentions a new association between two inherited rare disorders, NC and VWD type III, and this entity has not been reported before. Moreover, successful kidney transplantation in our patient supports the possibility of these procedures in hereditary clotting disorders. 


\section{Introduction}

Cystinosis is a lysosomal storage disease, which consists of three phenotypes. The most frequent form is nephropathic or infantile. Nephropathic cystinosis (NC) is an autosomal recessive disease that affects a gene named CTNS. Consequently, cystine crystals accumulate in many tissues, causing organ dysfunction. Usually, Fanconi syndrome (FS) presents at the first examination with progression to end-stage renal disease at age of 6-12 years [1].

Von willebrand disease (VWD) is a quantitative or qualitative abnormality in von willebrand factor (VWF), which is essential for platelet aggregation and stabilizing factor VIII. VWD is classified into three subtypes, type I is an autosomal dominant accounts for $70 \%$ of cases and type II variants account for $20-30 \%$ of cases. Type III is a rare subtype that is inherited as autosomal recessive [2].

This case presents the first case of a rare combination of NC and VWD type III (VWD3). Kidney transplantation is the best approach to treat NC; however, the dilemma was concomitant VWD3 and its bleeding complications. Renal graft (RG) was successfully implanted, and the patient was doing well after monitoring for six months.

\section{Case Report}

A 16-year-old patient was admitted to the Nephrology Department of Al Assad University Hospital due to uremic symptoms and potassium elevation. The patient medical history included NC, which was diagnosed at the age of nine months after full expression of Fancony Syndrome (FS) with slit-lamp revealed cystine crystal deposits (shown in Fig. 1). He could not afford to take cysteamine before. He also had VWD3, which was diagnosed after recurrent bleeding during the first year of life with laboratory tests that showed partial prothrombin time (aPTT) $>180 \mathrm{~s}$, factor VIII activity $<1 \%$, and von wellibrand factor (VWF: RCO) activity $<1 \%$.

Physical examination showed a blond-hair boy with a short stature $(157 \mathrm{~cm})$, weight $51 \mathrm{~kg}$, blood pressure 115/70 $\mathrm{mm} \mathrm{Hg}$, and oxygen saturation 98\%. Abnormal laboratory findings on admission are listed in Table 1.

Fig. 1. Slit-lamp examination on admission showed cystine crystal deposits on the cornea.

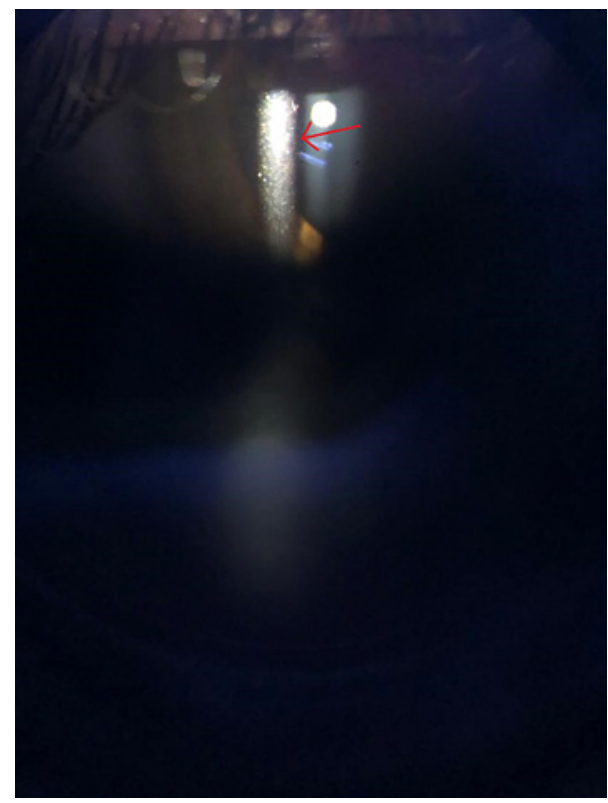




\section{Case Reports in Nephrology and Dialysis}

Table 1. Laboratory on admission

\begin{tabular}{l|l}
\hline Case Rep Nephrol Dial 2021;11:362-366 \\
\hline DOI: 10.1159/000520794 & $\begin{array}{l}\text { @ 2021 The Author(s). Published by S. Karger AG, Basel } \\
\text { www.karger.com/cnd }\end{array}$ \\
\hline
\end{tabular}

Alsultan et al.: Nephropathic Cystinosis with Von Willebrand Disease Type III

\begin{tabular}{llll}
\hline WBC & 5 & $\mathrm{Ur}$ & 197 \\
HB & 6.2 & $\mathrm{Cr}$ & 11.6 \\
PLT & 155 & $\mathrm{Na}$ & 139 \\
PT, \% & 70 & $\mathrm{~K}$ & 6.7 \\
PTT & $65 \mathrm{~s}$ & $\mathrm{P}$ & 6.2 \\
INR & 1.2 & $\mathrm{Ca}$ & 10 \\
Factor VIII Act, \% & 4 & $\mathrm{UA}$ & 8.5 \\
VWF Act, \% & 17.8 & PTH & 277 \\
BT & $>15$ min & Coag.T & $>10$ min \\
\hline
\end{tabular}

WBC, white blood count; HB, hemoglobin; PLT, platelets; PTT, partial prothrombin time; PT, prothrombin time; Factor VIII Act, factor VIII activity; VWF Act, von wellibrand factor activity; Ur, urea; $\mathrm{Cr}$, creatinine; Na, sodium; K, potassium; Ca, calcium; P, phosphorus; UA, uric acid; PTH, parathyroid hormone; Coag.T, coagulation time.

Dialysis access was inserted and followed by hemodialysis (HD) for four months with a proper infusion of blood products, which consisted of blood units, cryoprecipitate units and VWF concentrate contained factor VIII, when he had bleeding.

Because kidney transplantation is the standard therapy for NC [1], the patient was placed on our transplant list of candidates. As a preparation to receive a graft from his sister, infusion of rituximab and four sessions of plasmapheresis were done. Induction therapy on the day of the transplant was anti-thymocyte globulin (ATG) with methylprednisolone. The major fear was bleeding complications during or after renal transplantation surgery, therefore, a hematologic consult was requested.

The patient received a schedule of VWF/FVIII concentrates and cryoprecipitate units before and after transplantation (total 9 days) as recommended in hematologic guidelines $[3,4]$, along with proper laboratory tests. On the day of the procedure, FVIII: C level was $180 \%$ and aPTT was 35/sec. Postoperatively, on day 1, FVIII: C level was $145 \%$ and aPTT was 30/sec. On day 3, FVIII: C level was 105\% and aPTT was 30/sec. On day 5, FVIII: C level was $102 \%$ and aPTT was 34/sec. On day 7, FVIII: C level was $113 \%$ and aPTT was $25 / \mathrm{sec}$. The follow-up was only used aPTT and FVIII: $\mathrm{C}$ level due to the high cost of VWF: RCO, the shortened result of aPTT and elevated FVIII: $\mathrm{C}$ level was useful as an indirect indicator of VWF activity correction.

Postoperatively, $24 \mathrm{~h}$-urine output was $18 \mathrm{~L}$, blood pressure 110/80 $\mathrm{mm} \mathrm{Hg}$ and drain output was $250 \mathrm{~mL}$. Postoperative drugs were ATG on day 1 and 3 with mycophenolate mofetil, Tacrolimus, and Prednisolone. Foley catheter was removed on the fifth day, abdominal drain on sixth day and DJ stent on tenth day.

The patient was discharged with no bleeding and normal serum creatinine. Regular monitoring for 6 months was showed normal graft function without any bleeding events.

\section{Discussion}

$\mathrm{NC}$ is a rare disease with a prevalence nearly 1.6 per million and $>100$ mutations in the CTNS-gene [5]. Also, VWD3 is a rare disease that affects 1-5 per million [1]. Here, we describe a case where these two rare disorders coincide.

Kidney transplantation in patients with hereditary clotting disorders (HCDs) remains a medical dilemma. To our knowledge, there were only 4 cases that described kidney 
transplantation in hemophilic patients [6-9]. Three cases of hemophilia A reported successful renal transplantation without bleeding complications [7-9].

In a fourth case, massive intravesical hemorrhage was the main complication in the posttransplantation period [6]. In this case, however, the patient presents with a more complicated condition due to VWD3, which is associated with severe reduction or absence of VWF and marked decrease of factor VIII activity [2], and hence the need to prepare and administer extra blood products as needed to perform the transplantation.

In the context of NC, ESRD appears in early childhood and renal graft (RG) remains the treatment of choice with no risk of recurrence. Cysteamine, which prevents cystine accumulation, is usually withdrawn after transplantation [5].

The combination of VWD3 and NC in this patient made the decision of kidney transplantation quite difficult but might have a better outcome than chronic HD. From this point, RG was successfully implanted with careful monitoring for six months. This supports the possibility of kidney transplant in HCDs patients with rigorous application of hematologic recommendations $[3,4]$.

Also, the dialytic modality of choice in HCDs patients is controversial. Peritoneal dialysis does not require anticoagulants during sessions. Therefore, authors considered peritoneal dialysis is the treatment of choice for this population [10]. However, major complications, such as hemoperitoneum and peritonitis, often make this choice difficult [11].

This case reports successful pretransplant HD for four months without major complications. A previous study showed elevation of VWF levels in HD-patients and was correlated with an increase in cardiovascular mortality [12]; however, this elevation might prevent severe bleeding in patients with VWD. To date, this is the first case that mentions the combination of NC and VWD3, and no previous correlation between the two disorders was reported.

\section{Conclusion}

Here, we describe a new association between two inherited rare disorders, $\mathrm{NC}$, and VWD3, and this entity has not been reported before. Moreover, successful kidney transplantation for treat NC in a patient with VWD3 supports the ability of renal transplant in HCDs.

\section{Statement of Ethics}

Written informed consent was obtained from the father of the patient for publication of this case report and any accompanying images, and he has provided a copy of the consent form. The Ethics Committee of the Damascus University Research Center decided that ethics approval was not needed because it was not an experimental trial.

\section{Conflict of Interest Statement}

The authors have no conflicts of interest to declare.

\section{Funding Sources}

This research did not receive any specific Grant from funding agencies in the public, commercial, or not-for-profit sectors.

\section{Karger'}




\section{Author Contributions}

Dr. Mohammad alsultan writes the manuscript, literature search, and submit the article. Dr. Zeina Bdeir makes article corrections, literature search, and patient follow-up. Dr. Tahani Ali writes hematologic section and follow-up and literature search. Prof. Qusai Hasan makes article corrections, literature search, supervisor, and follow-up of the case.

\section{Data Availability Statement}

The data that support the findings of this study cannot be shared due to his father request. Data will be available from the corresponding author upon reasonable request.

\section{References}

1 Saudubray J-M, van den Berghe G, Walter JH. Inborn metabolic diseases diagnosis and treatment. 5th ed. Berlin-Heidelberg: Springer; 2012.

2 Lichtman MA, Kenneth Kaushansky M, Josef T, Prchal M, Levi MM, Burns LJ, et al., editors. Williams manual of hematology. 9th ed. McGraw-Hill Book Co.; 2017.

3 Hermans C, Altisent C, Batorova A, Chambost H, De Moerloose P, Karafoulidou A, et al. Replacement therapy for invasive procedures in patients with haemophilia: literature review, European survey and recommendations. Haemophilia. 2009;15(3):639-58.

4 Connell NT, Flood VH, Brignardello-Petersen R, Abdul-Kadir R, Arapshian A, Couper S, et al. Ash isth nhf wfh 2021 guidelines on the management of von willebrand disease. Blood Adv. 2021;5(1):301-25.

5 Langman CB, Barshop BA, Deschênes G, Emma F, Goodyer P, Lipkin G, et al. Controversies and research agenda in nephropathic cystinosis: conclusions from a "kidney disease: improving global outcomes" (KDIGO) controversies conference. Kidney Int. 2016;89(6):1192-203.

6 Gomperts ED, Malekzadeh MH, Fine RN. Dialysis and renal transplant in a hemophiliac. Thromb Haemost. 1981 Oct; 46(3):626-8.

7 El Bakkouri J, Mamdouh A, Faez S, Medkouri G, Ramdani B, Benchemsi N. [Kidney transplantation in a patient with haemophilia A]. Transfus Clin Biol. 2009;16(5-6):471-3.

8 Koene RA, Gerlag PG, Jansen JL, Moulijn AC, Skotnicki SH, Debruyne FJ, et al. Successful haemodialysis and renal transplantation in a patient with haemophilia A. Proc Eur Dial Transpl Assoc Eur Dial Transpl Assoc. 1977;14:401-6.

9 Malik S, Sadasukhi N, Sadasukhi TC, Gill APS. Renal transplant in a patient of severe hemophilia. Indian J Urol. 2021;37:87-9.

10 Bajo MA, del Peso G, Jiménez V, Aguilera A, Villar A, Jiménez C, et al. Peritoneal dialysis is the therapy of choice for end-stage renal disease patients with hereditary clotting disorders. Adv Perit Dial. 2000;16:170-3.

11 Esposito P, Rampino T, Gregorini M, Fasoli G, Gamba G, Canton AD. Renal diseases in haemophilic patients: pathogenesis and clinical management. Eur J Haematol. 2013;91(4):287-94.

12 Péquériaux NC, Fijnheer R, Gemen EF, Barendrecht AD, Dekker FW, Krediet RT, et al. Plasma concentration of von willebrand factor predicts mortality in patients on chronic renal replacement therapy. Nephrol Dial Transplant. 2012;27(6):2452-7. 